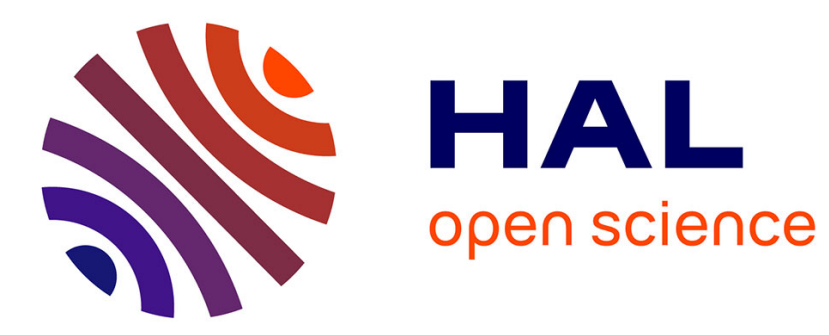

\title{
Stability and phase transitions in a mathematical model of Duchenne muscular dystrophy \\ Guido Dell'Acqua, Filippo Castiglione
}

\section{To cite this version:}

Guido Dell'Acqua, Filippo Castiglione. Stability and phase transitions in a mathematical model of Duchenne muscular dystrophy. Journal of Theoretical Biology, 2009, 260 (2), pp.283. 10.1016/j.jtbi.2009.05.037 . hal-00554624

\section{HAL Id: hal-00554624 \\ https://hal.science/hal-00554624}

Submitted on 11 Jan 2011

HAL is a multi-disciplinary open access archive for the deposit and dissemination of scientific research documents, whether they are published or not. The documents may come from teaching and research institutions in France or abroad, or from public or private research centers.
L'archive ouverte pluridisciplinaire HAL, est destinée au dépôt et à la diffusion de documents scientifiques de niveau recherche, publiés ou non, émanant des établissements d'enseignement et de recherche français ou étrangers, des laboratoires publics ou privés. 


\section{Author's Accepted Manuscript}

Stability and phase transitions in a mathematical model of Duchenne muscular dystrophy

Guido Dell'Acqua, Filippo Castiglione

PII: $\quad$ S0022-5193(09)00250-1

DOI: $\quad$ doi:10.1016/j.jtbi.2009.05.037

Reference: $\quad$ YJTBI 5580

To appear in: $\quad$ Journal of Theoretical Biology

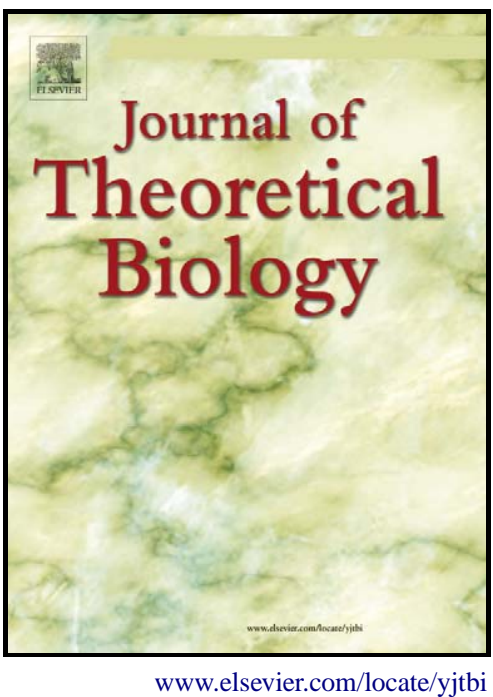

Received date: $\quad 8$ March 2009

Revised date: $\quad 16$ May 2009

Accepted date: 23 May 2009

Cite this article as: Guido Dell'Acqua and Filippo Castiglione, Stability and phase transitions in a mathematical model of Duchenne muscular dystrophy, Journal of Theoretical Biology, doi:10.1016/j.jtbi.2009.05.037

This is a PDF file of an unedited manuscript that has been accepted for publication. As a service to our customers we are providing this early version of the manuscript. The manuscript will undergo copyediting, typesetting, and review of the resulting galley proof before it is published in its final citable form. Please note that during the production process errors may be discovered which could affect the content, and all legal disclaimers that apply to the journal pertain. 


\title{
Stability and phase transitions in a mathematical model of Duchenne muscular dystrophy
}

\author{
Guido Dell'Acqua and Filippo Castiglione \\ Institute for Computing Applications "M. Picone", \\ National Research Council (CNR), \\ Viale del Policlinico 137, 00161 - Rome, Italy \\ $\{$ g.dellacqua, f. castiglione\}@iac.cnr.it
}

June 9, 2009

\begin{abstract}
We present a mathematical model to investigate the role of the immune system in the Duchenne muscular dystrophy disease. It is based on the assumption that the immune system contributes to the tissue damage and indeed its interaction with the muscle tissue after an initial endogenous damage can be described as a predator-prey system showing typical oscillations. In this article we investigate the dynamical properties of the system. We find that, for a biologically relevant parameters range, it shows two phase-transitions between qualitative different behaviors corresponding to complete recover or to a state where muscle regeneration and degeneration coexist.
\end{abstract}

\section{Introduction}

The Duchenne Muscular Dystrophy (DMD) is a genetic disorder that leads to the absence of the protein dystrophin $[1,2]$. This protein is prominent in muscle cells as it binds with several other proteins in the muscle cell membrane to form what is called the dystrophin glycoprotein complex. The role of this complex is yet unknown, but many researchers believe that it provides mechanical stability for the muscle cell membrane or that it is involved in important intra-cellular signaling mechanisms $[3,4,5]$.

Mechanical injury and membrane defects are important factors promoting dystrophic disease pathology, but do not fully explain DMD disease onset and progression [6, 7]. Inflammatory-mediated mechanisms, which result in muscle cell death and mechanisms leading to fibrosis appear to be initiators of lesions in dystrophin-deficient muscle.

In a current view of the DMD pathogenesis it is believed that the immune response is to blame, at least in part, for the muscle damage. In favor of this hypothesis, microscopic analysis of dystrophic muscle tissue reveals that it is often infiltrated with a large numbers of immune cells including $\mathrm{T}$ lymphocytes (both helper and cytotoxic), macrophages and several others [8].

We have constructed a mathematical model that follows this hypothesis, with the only difference that the cytotoxic activity of the immune system against the muscle tissue is initially ignited by a genetic defect worsened by, for example, mechanical stress. In this setting the pathology develops through a cascade of events that can be roughly summarized as follows: macrophages initially infiltrates the damaged muscle tissue and, while cleaning cellular debris, they call for $\mathrm{CD} 4^{+} \mathrm{T}$ cells that in turn call for $\mathrm{CD} 8^{+} \mathrm{T}$ cells. Also called cytotoxic cells, $\mathrm{CD} 8^{+} \mathrm{T}$ lymphocytes have the ability to destroy targeted cells. In this case, they target also healthy muscle cells provoking more and more damage. 
On the basis of this assumptions we have built a mathematical model that includes the concentration of macrophages $(M)$, helper $\mathrm{CD} 4^{+}$lymphocytes $(H)$, of cytotoxic $\mathrm{CD} 8^{+}$lymphocytes $(C)$ and the percentage of normal $(N)$, damaged $(D)$ and regenerating $(R)$ muscle cells.

The interaction between immune system and muscle cells follows a predator-prey scheme where the muscle cells are prey for the immune cytotoxic lymphocytes that, on the other hand, can be seen as the predators. This model has been validated against direct comparison with time course data from dystrophic muscles in "MDX" mice [9], that have been validated as genetic models of DMD [3, 10] since they develop muscle lesions during early disease stages that resemble those of DMD patients [11].

In the present work we present the mathematical model, we look for qualitative dynamical properties of the system and discuss possible therapeutic applications via pharmacological or cytological treatment.

The paper is organized as follows: in section 2 we describe the system of ODEs and perform a nondimensionalization of the model. In section 3 we study the linear stability of the "limiting system" near its stationary points. Our findings are corroborated in section 4, where we show the results of the numerical integration. Finally, section 5 summarizes and gives possible therapeutic hints.

\section{Statement of the problem and non-dimensionalization}

We model the mesoscopic interaction between the immune system (macrophages $M, \mathrm{~T}$ helper $H$ and $\mathrm{T}$ cytotoxic lymphocytes $C$ ) and the percentage of normal $N$, damaged $D$ and regenerating $R$ muscle cells. The model equations are

$$
\begin{aligned}
\frac{d M}{d t} & =a_{1}+b_{1} M D-d_{1} M \\
\frac{d H}{d t} & =a_{2}+b_{2} M D-d_{2} H \\
\frac{d C}{d t} & =b_{3} H D-d_{3} C \\
\frac{d N}{d t} & =a_{4} R-b_{4} C N-h \Delta N \\
\frac{d D}{d t} & =b_{4} C N-b_{5} M D-d_{4} D+h \Delta N
\end{aligned}
$$

complemented by the conservation law

$$
N+D+R=100
$$

and by the following initial conditions

$$
M(0)=M_{0}, \quad H(0)=H_{0}, \quad C(0)=0, \quad N(0)=100, \quad D(0)=0, \quad R(0)=0 .
$$

Equation (6) implies that the total number of cells is constant. Given that the experimental data for these quantities are expressed as percentages [9], it is straightforward to fix this constant to 100 . It follows also that $N(0)=100$. Moreover, let us suppose that

$$
\begin{aligned}
& a_{1}=d_{1} M(0) \\
& a_{2}=d_{2} H(0) .
\end{aligned}
$$

Conditions (7)-(8) imply that if $h=0$, i.e., there is no initial damage, then the initial state is a stationary stable state.

Notice that the system (1)-(6) is non-autonomous because of the presence in equation (5) of the function $\Delta=\Delta(t)$ that represents an impulse-like damage that initiates the immune response and then vanishes. The biological rationale for this choice is, for example, a mechanical stress of the muscle tissue on top of the 
genetic predisposition to the disease.

To model the process of accumulation of damage in the muscle tissue, that is composed by a large number of muscle cells, we resorted to a log-normal function. The reason for this choice is that log-normal distributions can be theoretically expected under the assumption of a "degradation process" resulting from failures [12]. Therefore we model the initial damage as the following function

$$
\Delta(t, m, \sigma)=\frac{1}{\sigma t \sqrt{2 \pi}} \exp \left(-\frac{1}{2 \sigma^{2}}(\log t-m)^{2}\right)
$$

with parameters $m$ and $\sigma$.

The system (1)-(6) can be described in few words as follows. Equations (1)-(3) represent the rate of change of the immune cell counts of macrophages, $\mathrm{CD}^{+}$and $\mathrm{CD} 8^{+} \mathrm{T}$ cells, respectively. For example, equation (1) says that at a given time $t$ while $d_{1} M$ macrophages age and die, they are replenished from their source at a rate $a_{1}$ cells per week. In presence of damage $D>0$, the term $b_{1} M D$ represents the local recruitment of cells by inflammatory mechanisms. Equation (2) and (3) are similar. Equations (4)-(5) represent the rate of change of the percentage of normal, damaged and regenerating muscle cells. Equation (5) reflects our assumption that the muscular tissue damage initially starts in a small percentage $\alpha N$ of the normal muscle fibers. Then, when $\mathrm{CD}^{+}{ }^{+} \mathrm{T}$ cells infiltrate the tissue they create more damage as a percentage of the normal cells $b_{4} C N$. Damaged fibers are cleared out both by macrophages at the rate $b_{5} M D$ or by other degradation mechanisms at the rate $d_{4} D$. Equation (4) implies that healthy normal muscle cells $N$ are replenished from the generating fibers $R$ at the rate $a_{4} R$ and, as already mentioned, are damaged at the rate $b_{4} C N+\alpha N$. Equation (6) says that a cell can be either normal, damaged or regenerating.

It is worth to note that the muscle damage raises in presence of $\mathrm{CD} 8^{+} \mathrm{T}$ cells, which increase with the $\mathrm{CD} 4^{+}$ $\mathrm{T}$ cells (see equation (3)), which, in their turn, are boosted by a high level of macrophages (see equation (2)). Therefore macrophages contribute to both physiological and pathological states since they clean cellular debris to favor cell regeneration and at the same time they foster an immune reaction that in its turn cause more damage to the tissue destroying healthy muscle fibers.

The system of equations has 14 free parameters (12 in equations (1)-(6) plus 2 in (9)) and 2 conditions. This leaves out 12 free parameters. The values of such parameters have been estimated using COPASI [13] by applying its built-in optimization methods, combining the time course data for several different dystrophic muscles of mice in the age range 14-84 days and identifying others time course data sets from the literature $[8,11,14]$. The resulting estimated parameters are shown in Table 1.

The initial conditions for $M$ and $H$ are taken from the literature as follows:

$$
M_{0}=429 \text { cells } \mathrm{mm}^{-3}, \quad H_{0}=6.25 \text { cells } \mathrm{mm}^{-3}
$$

while $C_{0}=0$ means that in absence of damage no $\mathrm{CD}^{+} \mathrm{T}$ cells infiltrate the muscle tissue.

To analyze the model, it is convenient to convert all equations to be dimensionless. Let

$$
t=t_{c} \tilde{t}, \quad M=M_{c} \widetilde{M} \quad H=H_{c} \widetilde{H}, \quad C=C_{c} \widetilde{C}, \quad N=N_{c} \widetilde{N}, \quad \Delta=\Delta_{c} \widetilde{\Delta}
$$

and analogously for the initial conditions. Here $\widetilde{M}, \widetilde{H}, \widetilde{C}, \widetilde{N}, \widetilde{D}, \widetilde{R}$ and $\widetilde{\Delta}$ are dimensionless variables. Substituting (10) in (1)-(6) and incorporating conditions in (7)-(8) we get: 


\section{ACCEPTED MANUSCRIPT}

\begin{tabular}{|c|c|c|c|c|}
\hline \multicolumn{5}{|c|}{ Model parameters } \\
\hline Entity & Parameter & Description & Value & Units \\
\hline $\mathbf{M}$ & $\begin{array}{l}a_{1} \\
b_{1} \\
d_{1}\end{array}$ & $\begin{array}{l}\text { Turnover rate of macrophages } \\
\text { Infiltration rate of macrophages } \\
\text { Death rate of macrophages }\end{array}$ & $\begin{array}{l}d_{1} M(0) \\
0.950788 \\
0.912485\end{array}$ & $\begin{array}{l}c \quad w^{-1} \mathrm{~mm}^{-3} \\
c^{-1} w^{-1} \mathrm{~mm}^{3} \\
w^{-1}\end{array}$ \\
\hline $\mathbf{H}$ & $\begin{array}{l}a_{2} \\
b_{2} \\
d_{2}\end{array}$ & $\begin{array}{l}\text { Turnover rate of CD } 4+\mathrm{T} \text { cells } \\
\text { Damage-driven proliferation rate of } \mathrm{CD} 4+\mathrm{T} \text { cells } \\
\text { Death rate of CD } 4+\mathrm{T} \text {-cells }\end{array}$ & $\begin{array}{l}d_{2} H(0) \\
0.0483312 \\
0.999999\end{array}$ & $\begin{array}{lll}c & w^{-1} & \mathrm{~mm}^{-3} \\
c^{-1} & w^{-1} & \mathrm{~mm}^{3} \\
c & w^{-1} & \mathrm{~mm}^{-3}\end{array}$ \\
\hline $\bar{C}$ & $\begin{array}{l}b_{3} \\
d_{3}\end{array}$ & $\begin{array}{l}\text { Damage-driven proliferation rate of } \mathrm{CD} 4+\mathrm{T} \text { cells } \\
\text { Death rate of CD8 }+\mathrm{T} \text { cells }\end{array}$ & $\begin{array}{l}0.08065 \\
0.999999\end{array}$ & $\begin{array}{l}c^{-1} w^{-1} m m^{3} \\
w^{-1}\end{array}$ \\
\hline $\mathbf{N}$ & $\begin{array}{c}a_{4} \\
b_{4} \\
h \\
\sigma \\
m\end{array}$ & $\begin{array}{l}\text { Generation rate of healthy fibers } \\
\text { Cytotoxicity degradation rate } \\
\text { Strength of impulse-like initial damage } \\
\text { Standard deviation of the initial damage } \\
\text { Time of the peak of the initial damage }\end{array}$ & $\begin{array}{l}0.17 \\
0.0041864 \\
0.19119 \\
0.609114 \\
0.945333\end{array}$ & $\begin{array}{l}w^{-1} \\
c^{-1} w^{-1} m m^{3} \\
w^{-1}\end{array}$ \\
\hline $\bar{D}$ & $\begin{array}{l}b_{5} \\
d_{4}\end{array}$ & $\begin{array}{l}\text { Cleaning rate by macrophages } \\
\text { Physiological cleaning rate }\end{array}$ & $\begin{array}{l}0.000664372 \\
1.20001\end{array}$ & $\begin{array}{ll}c^{-1} & w^{-1} m^{3} \\
c^{-1} & w^{-1} m^{3}\end{array}$ \\
\hline
\end{tabular}

Table 1: Parameters of the model in equations (1)-(6) estimated in [9]. Unit $c$ is for cells and $w$ for weeks.

$$
\begin{aligned}
\frac{d \widetilde{M}}{d t} & =d_{1} t_{c}\left(\widetilde{M}_{0}-\widetilde{M}\right)+b_{1} D_{c} t_{c} \widetilde{M} \widetilde{D} \\
\frac{d \widetilde{H}}{d t} & =d_{2} t_{c}\left(\widetilde{H}_{0}-\widetilde{H}\right)+\frac{b_{2} t_{c} M_{c} D_{c}}{H_{c}} \widetilde{M} \widetilde{H} \\
\frac{d \widetilde{C}}{d t} & =\frac{b_{3} t_{c} H_{c} D_{c}}{C_{c}} \widetilde{H} \widetilde{D}-d_{3} t_{c} \widetilde{C} \\
\frac{d \widetilde{N}}{d t} & =\frac{a_{4} t_{c} R_{c}}{N_{c}} \widetilde{R}-b_{4} t_{c} C_{c} \widetilde{C} N t-h t_{c} \Delta_{c} \widetilde{\Delta} \widetilde{N} \\
\frac{d \widetilde{D}}{d t} & =\frac{b_{4} t_{c} C_{c} N_{c}}{D_{c}} \widetilde{C} \widetilde{N}-b_{5} t_{c} M_{c} \widetilde{M} \widetilde{D}-d_{4} t_{c} \widetilde{D}+\frac{h t_{c} \Delta_{c} N_{c}}{D_{c}} \widetilde{\Delta}
\end{aligned}
$$

and

$$
N_{c} \tilde{N}+D_{c} \widetilde{D}+R_{c} \widetilde{R}=100 .
$$

Now we choose $t_{c}, M_{c}, H_{c}, C_{c}, N_{c}, D_{c}$ and $R_{c}$ such that all variables are of the order of unity while reducing the number of free parameters. For what concerns $N_{c}, D_{c}$ and $R_{c}$, being percentages, we are left to set $N_{c}=D_{c}=R_{c}=100$

Moreover, we set:

$$
t_{c}=\frac{1}{d_{1}} ; \quad M_{c}=\frac{d_{1}}{b_{5}} ; \quad H_{c}=\frac{10^{2} b_{2}}{b_{5}} ; \quad C_{c}=\frac{d_{1}}{b_{4}} ; \quad \Delta_{c}=d_{1} ;
$$

Finally, having chosen a log-normal impulse $\Delta$ as in (9) we have

$$
\Delta=\Delta(t, m, \sigma)=\frac{1}{t_{c}} \Delta\left(\tilde{t}, m-\log t_{c}, \sigma\right)=\frac{1}{t_{c}} \widetilde{\Delta} .
$$



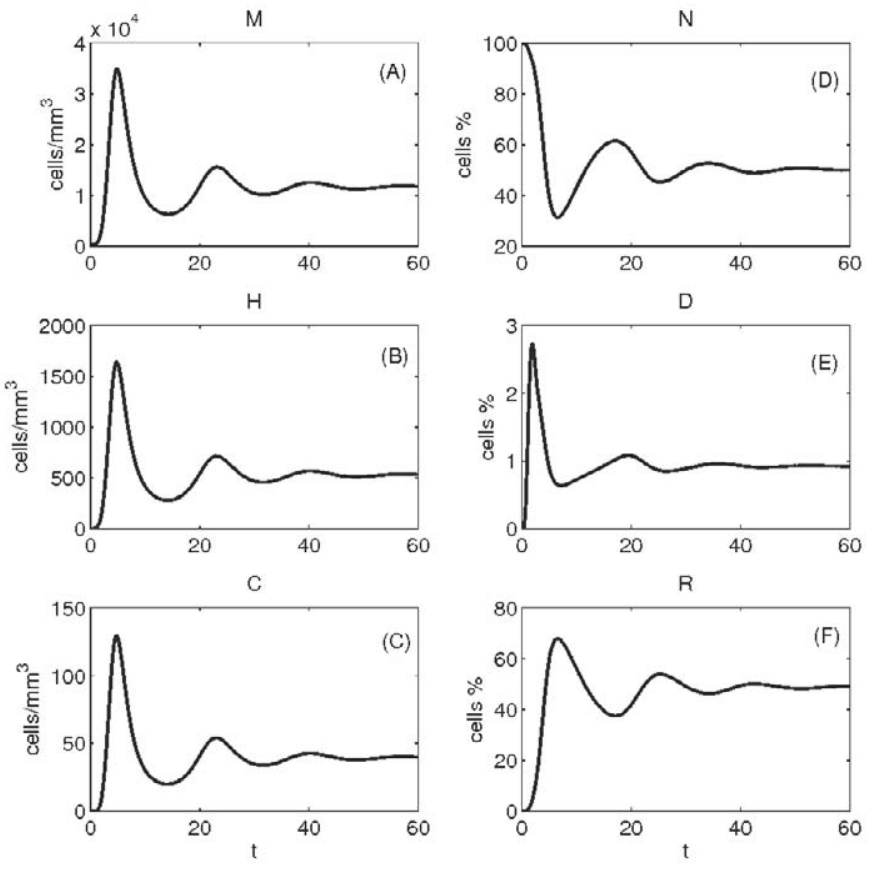

Figure 1: Dynamics of the system (1)-(6) with values of the parameters from Table 1. Plots on the left show concentrations of: A) Macrophages; B) CD4+ T cells; C) CD8+ T cells. Plots on the right show percentages of: D) Normal cells; E) Damaged cells; F) Regenerating cells.

Therefore the dimensionless model can be written (dropping tildes):

$$
\begin{aligned}
& \frac{d M}{d t}=M_{0}-M+\beta_{1} M D \\
& \frac{d H}{d t}=\beta_{2}\left(H_{0}-H\right)+M D \\
& \frac{d C}{d t}=\beta_{3} H D-\beta_{4} C \\
& \frac{d N}{d t}=\beta_{5} R-C N-h \Delta N \\
& \frac{d D}{d t}=C N-M D-\beta_{6} D+h \Delta N
\end{aligned}
$$

and

where

$$
N+D+R=1
$$

$$
\beta_{1}=\frac{10^{2} b_{1}}{d_{1}} ; \quad \beta_{2}=\frac{d_{2}}{d_{1}} ; \quad \beta_{3}=\frac{10^{4} b_{2} b_{3} b_{4}}{b_{5} d_{1}^{2}} ; \quad \beta_{4}=\frac{d_{3}}{d_{1}} ; \quad \beta_{5}=\frac{a_{4}}{d_{1}} ; \quad \beta_{6}=\frac{d_{4}}{d_{1}} .
$$

Note that all variables are of the order of unity and the number of free parameters is reduced to 7 .

The dynamics of the model, with parameters values as in Table 1, is shown in Fig. 1. 

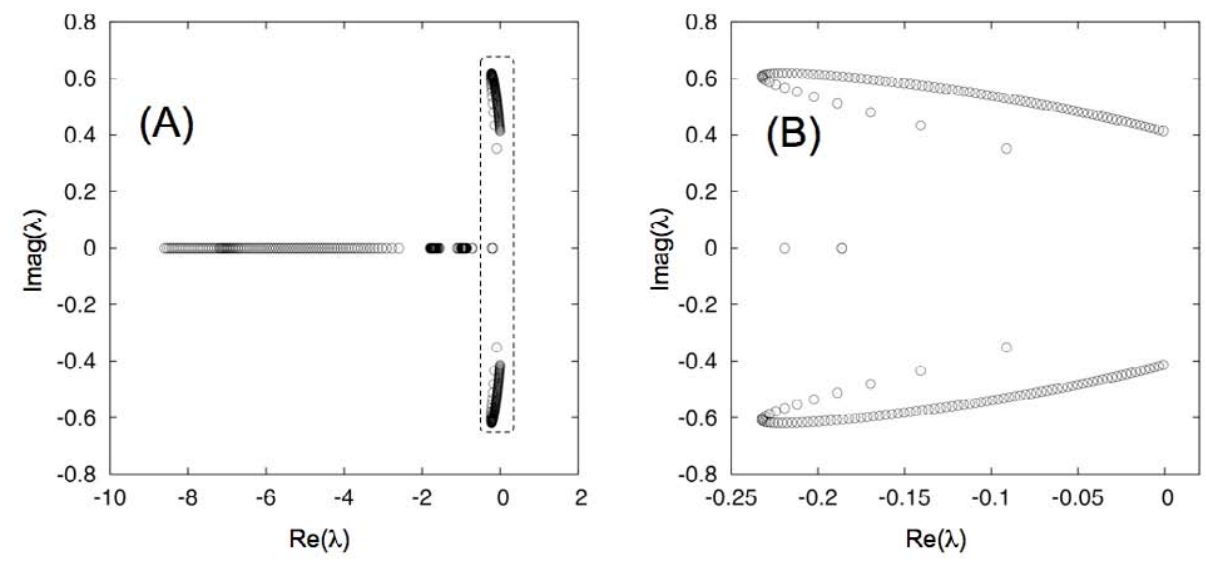

Figure 2: Panel A: evolution of the eigenvalues of the stable stationary solution of (18)-(22) for 100 values of $M_{0}$ between 0 and 8000; other parameters values are as in Table 1, except for $\beta_{1}=10,456$. Panel B shows the zoom of the dashed area close to the origin in panel A.

\section{Stability of the "limiting system"}

Let us consider the dynamical system (11)-(16) obtained by setting $h=0$ in equations (14)-(15), i.e., in absence of the mechanical stress that starts the immune system reaction. This can be considered as the "limiting system" associated to (11)-(16), meaning that after a transient period for $t>\hat{t}$ the dynamics is "almost" fully governed by the system

$$
\begin{aligned}
\frac{d M}{d t} & =M_{0}-M+\beta_{1} M D \\
\frac{d H}{d t} & =\beta_{2}\left(H_{0}-H\right)+M D \\
\frac{d C}{d t} & =\beta_{3} H D-\beta_{4} C \\
\frac{d N}{d t} & =\beta_{5}(1-N-D)-C N \\
\frac{d D}{d t} & =C N-M D-\beta_{6} D
\end{aligned}
$$

where we have incorporated the conservation law (16) in equation (21). Now we look for stationary solutions. Setting to zero the left hand sides of (18)-(22) it can be easily seen that depending on the parameters values the system admits two or four stationary solutions. Indeed, all variables can be expressed as functions of $D$ and substituting in (22) we are left with an homogeneous polynomial of degree 4 that has, besides 0 , one or three more real roots.

To perform a linear stability analysis, let us linearize the limiting system (18)-(22) near a the stationary state $\left(M^{*}, H^{*}, C^{*}, D^{*}, N^{*}, R^{*}\right)$ by setting

$$
\begin{array}{rlrl}
M & =M^{*}+\varepsilon \tilde{m}, & H=M^{*}+\varepsilon \tilde{h}, \quad C=C^{*}+\varepsilon \tilde{c}, \\
N & =N^{*}+\varepsilon \tilde{n}, & D=D^{*}+\varepsilon \tilde{d}, &
\end{array}
$$



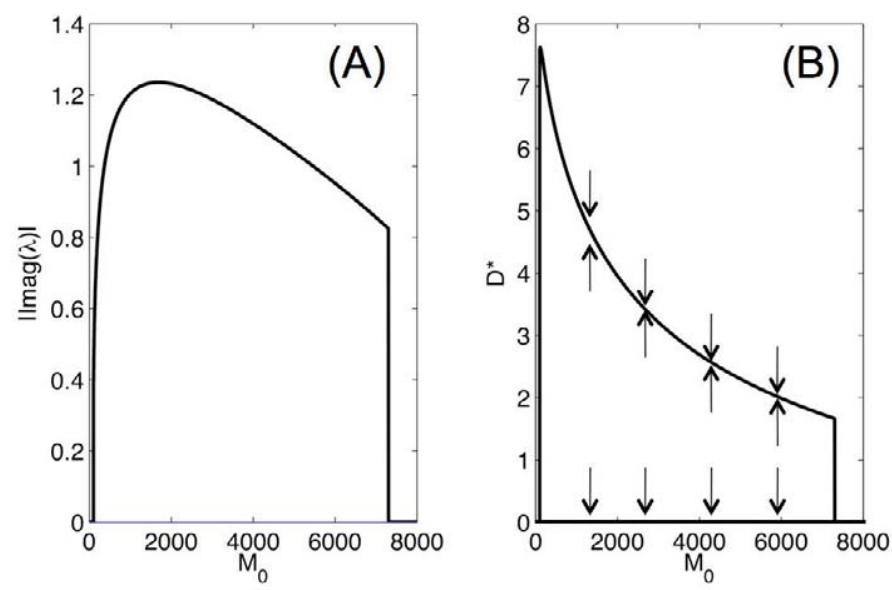

Figure 3: Panel A: Absolute value of the imaginary part of the complex eigenvalue of (28) as a function of $M_{0}$; Panel B: Corresponding plot of the stable stationary values of $\mathrm{D}$ (for $M_{0} \in[99,7304]$ we have two stationary solutions whereas for $M_{0}<99$ and $M_{0}>7304$ just one); in both plots parameters are as in Table 1 except for $\beta_{1}=10.456$.

with $\varepsilon \ll 1$. Substituting in (18)-(22), we get, at leading order,

$$
\begin{aligned}
\tilde{m}^{\prime} & =\left(\beta_{1} D^{*}-1\right) \tilde{m}+\beta_{1} M^{*} \tilde{d} \\
\tilde{h}^{\prime} & =D^{*} \tilde{m}-\beta_{2} \tilde{h}+M^{*} \tilde{d} \\
\tilde{c}^{\prime} & \left.=\beta_{3} D^{*}-\beta_{4}\right) \tilde{c}+\beta_{3} H^{*} \tilde{d} \\
\tilde{n}^{\prime} & =-N^{*} \tilde{c}-\left(\beta_{5}+C^{*}\right) \tilde{n}-\beta_{5} \tilde{d} \\
\tilde{d}^{\prime} & =-D^{*} \tilde{m}-+N^{*} \tilde{c}+C^{*} \tilde{n}-\left(M^{*}+\beta_{6}\right) \tilde{d} .
\end{aligned}
$$

Then, setting

$$
\begin{aligned}
\tilde{m}=\hat{m} \mathrm{e}^{\lambda t}, \quad \tilde{h}=\hat{h} \mathrm{e}^{\lambda t}, \quad \tilde{c}=\hat{c} \mathrm{e}^{\lambda t}, \\
\tilde{n}=\hat{n} \mathrm{e}^{\lambda t}, \quad \tilde{d}=\hat{d} \mathrm{e}^{\lambda t},
\end{aligned}
$$

and substituting in (23)-(27) we find

$$
A\left(\begin{array}{c}
\hat{m} \\
\hat{h} \\
\hat{c} \\
\hat{n} \\
\hat{d}
\end{array}\right)=\lambda\left(\begin{array}{c}
\hat{m} \\
\hat{h} \\
\hat{c} \\
\hat{n} \\
\hat{d}
\end{array}\right)
$$

where

$$
A=\left(\begin{array}{ccccc}
\beta_{1} D^{*}-1 & 0 & 0 & 0 & \beta_{1} M^{*} \\
D^{*} & -\beta_{2} & 0 & 0 & M^{*} \\
0 & \beta_{3} D^{*} & -\beta_{4} & 0 & \beta_{3} H^{*} \\
0 & 0 & -N^{*} & -C^{*}-\beta_{5} & -\beta_{5} \\
-D^{*} & 0 & N^{*} & C^{*} & -M^{*}-\beta_{6}
\end{array}\right)
$$


The eigenvalues of $A$ are the roots of its characteristic polynomial. Therefore it is easy to check that in the case of one root, this is either unstable or not admissible (i.e., value less than zero), whereas in the case of three roots we can have either that one is stable and two are unstable or all three are unstable.

Summarizing, the limiting system can have regions of bistability. If $h=0$ then the system remains in its initial state. If $h>0$, the dynamics begins. When the resulting value of $D$ rises above a certain threshold (e.g., one unstable stationary point) then the system is driven to the other stationary stable state (see figure 4).

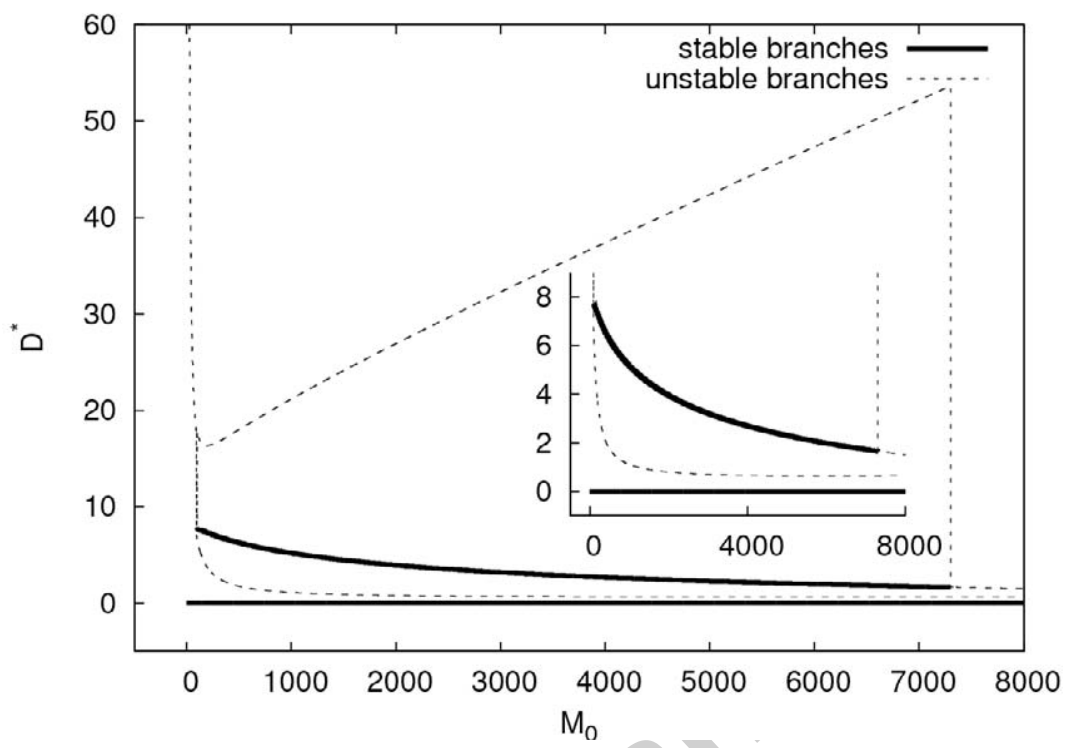

Figure 4: Bifurcation diagram: stable branches (solid lines), unstable branches (dashed lines). The inset is a zoom of the larger picture. Parameters are as in figure 2.

If the stationary solution coincides with the initial state then all of the eigenvalues are real and negative whereas the situation changes when we study the other stable stationary solution.

Since it is widely accepted that the immune system promotes injury of dystrophin-deficient muscle [14], we restricted our study to the 2-dimensional subspace of the parameters $M_{0} \times \beta_{1}$, in view of finding possible therapeutic treatments. More in details, $M_{0}$ is the initial amount of $M$, i.e., the number of macrophages in a healthy muscle tissue, while $\beta_{1}=10^{2} b_{1} / d_{1}$ (non-dimensional) represents the "sensitivity" of the immune system to the induced damage, normalized with respect to the death rate of these cells.

In Fig. (2) we show the eigenvalues of the matrix associated to the linearization of the limiting system in equations (18)-(22) for different values of $M_{0}$. For small values of $\beta_{1}$, when $M_{0}$ gets closer to the first threshold value, the imaginary part of two eigenvalues becomes different from zero. This is where the system experiments a first phase transition. At the second threshold value, the imaginary part of these eigenvalues becomes zero, hence we have the other phase transition (see Fig. (3)). For larger values of $\beta_{1}$, the first part of this process is skipped, i.e., the system experiments only the second phase transition. For even larger values of $\beta_{1}$ the only stationary stable solution is the initial state. In Fig. (5), panels $\mathrm{A}, \mathrm{C}$ and E, we show the stationary value of $D$ as a function of the two parameters $M_{0}$ and $\beta_{1}$. 


\section{Numerical solution of the full system}

Let us now consider the non-autonomous system (1)-(6). We have used a standard variable-order solver of the MATLAB package, ode15s [15] to perform the numerical integration. The results agree with the linear stability analysis discussed above, as we show in Fig. (5), panels B, D and F, where we have depicted the stationary values of $D$ as a function of the two parameters $M_{0}$ (dimensional) and $\beta_{1}$. Moreover, starting from the parameter values in table Table 1 we have performed a simple sensitivity analysis by perturbing slightly the parameters one at a time and observing the resulting dynamics (not shown). It turned out, as expected, that the stationary solutions are robust with respect to the magnitude of the perturbations.

In Fig. (5), if we compare panels $\mathrm{A}, \mathrm{C}$ and $\mathrm{E}$ with panels $\mathrm{B}, \mathrm{D}$ and $\mathrm{F}$, we see that the phase transitions in the latter cases are somehow smoother. This depends on the fact that the strength of the impulse is not always sufficient to drive the system to the basin of attraction of the other stable state. Therefore the linear stability analysis gives us a view on the possible stable stationary states of the system; the actual chance to reach those states depends on how we stress the system.

\section{Conclusions}

Duchenne Muscular Dystrophy is an excellent candidate for mathematical and computer modeling. Firstly, it can be used as a paradigm for studying the inflammatory component of several other diseases, such as cancer or cardiovascular disease. Secondly, DMD is an important disease for which representative mouse models are available (i.e., MDX mice), providing rich experimental data for modeling. At the same time, no mathematical models for DMD or related diseases have been built to date.

The ultimate goal is to identify suitable therapeutic targets to blunt or prevent DMD in humans; thus, mathematical and computer simulation results from the mouse model can provide invaluable guidance for studies in humans.

In this paper we have constructed a model of five ODEs, plus a conservation law, to investigate the role of the immune system in the Duchenne muscular dystrophy. The model has been validated against experimental data from MDX mice as described elsewhere [9].

With a simple linear stability argument we have found that the model may present regions of bistability corresponding to either complete recover or to a state where massive cell degeneration and regeneration coexist. We have identified such region as a function of two parameters that are among those controlling the strength of the immune response. The numerical solution of the full system confirms our analysis.

In our model the pathology initiates with an impulse that may (or may not) drive the system from the healthy stationary state to the basin of attraction of the other stable stationary state.

The therapeutic insights of this analysis are interesting. It would suffice to drive the system (via a pharmacological or cytological treatment) into the mono-stability region of complete recover, or to a region where the basin of attraction of the other stable solution is too far to be reached with a physiological stress, so that the system falls back into the healthy region. To this end, it is worth to mention the work in [14] where the authors proved by in vivo experiments the active role of the macrophages in lysing the muscle membranes by depleting them and then assessing the occurrence of membrane lesions.

\section{Acknowledgments}

G. D. acknowledges support of the EC under the contract "P6-2005-NEST-PATH, No.043241 (ComplexDis)". A. Jarrah and N. Evans are kindly acknowledged for fruitful discussions and suggestions. 


\section{References}

[1] D. J. Blake, A. Weir, S. E. Newey And K. E. Davies (2002) Function and genetics associated with DMD. DMD is an excellent candidate for mathematical and computer of dystrophin and dystrophin-related proteins in muscle. Physiol Rev. 82, 291-329

[2] J. G. Tidball and W.-H. Michelle (2004) Evolving therapeutic strategies for Duchenne muscular dystrophy: targeting downstream events. Pediatr Res. 56, 831-841

[3] M. Durbeej And K. P. Campbell (2002) Muscular dystrophies involving the dystrophinglycoprotein complex: an overview of current mouse models. Curr Opin Genet Dev. 12, 349-361

[4] S. A. OAK, Y. W.Zhou And H. W. Jarrett (2003) Skeletal muscle signaling pathway through the dystrophin glycoprotein complex and Rac1. J Biol Chem. 278, 39287-39295.

[5] V. Straub and K. P. Campbell (1997) Muscular dystrophies and the dystrophin- glycoprotein complex. Curr Opin Neurol. 10, 168-175.

[6] C. Pasternak, S. Wong And E. L. Elson (1995) Mechanical function of dystrophin in muscle cells. J Cell Biol. 128, 355-361.

[7] B. J. Petrof, J. B. Shrager, H. H. Stedman, A. M. Kelly and H. L. Sweeney (1993) Dystrophin protects the sarcolemma from stresses developed during muscle contraction. PNAS. 90, 3710-3714.

[8] M. J. Spencer, E. Montecino-Rodriguez, K. Dorshkind And J. G. Tidball (2001) Helper $(\mathrm{CD} 4+)$ and Cytotoxic (CD8+) T cells Promote the Pathology of Distrophin-Deficient Muscle. Clin Immunol., 98(2), 235-243.

[9] A. Jarrah, N. Evans, R. Laubenbacher A mathematical model of Duchenne Muscular Dystrophy in MDX mice, in preparation (2009).

[10] C. A. Collins And J. E. Morgan (2003) Duchenne's muscular dystrophy: animal models used to investigate pathogenesis and develop therapeutic strategies. Int $J$ Exp Pathol. 84, 165-172

[11] M. J. Spencer, C. M. Walsh, K. A. Dorshkind, E. M. Rodriguez and J. G. Tidball (1997) Myonuclear apoptosis in dystrophic mdx muscle occurs by perforin-mediated cytotoxicity. J Clin Invest. 99(11), pp. 2745-2751.

[12] A. N. Kolmogorov (1941) Uber das logarithmisch normale Verteilungsgesetz der Dimensionen der Teilchen bei Zerstuckelung. Dockl. Akad. Nauk. SSSR 31, 99-101.

[13] S. Hoops, S. Sahle, R. Gauges, C. Lee, J. Pahle, N. Simus, M. Singhal, L. Xu, P. Mendes, U. Kummer (2006) COPASI-a COmplex PAthway SImulator. Bioinformatics 22(24), 3067-3084.

[14] M. Wehling, M. J Spencer and J. G. Tidball (2001) A nitric oxide synthase transgene ameliorates muscular distrophy in mdx mice. J. Cell Biol. 15(1), 123-131.

[15] The MathWorks, www.mathworks.com. 

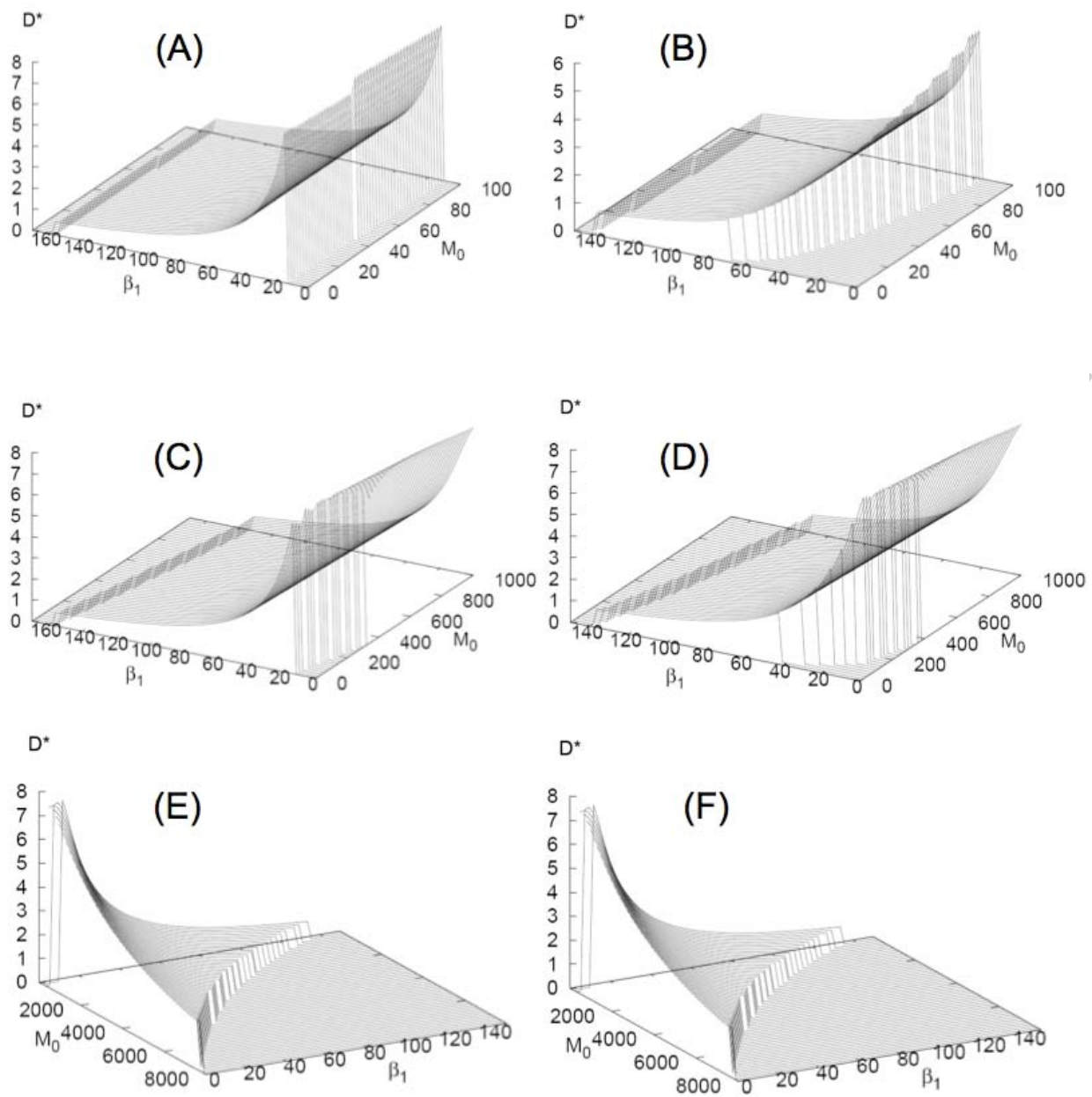

Figure 5: Panels A, C and D: stationary values of $D$ obtained by numerical integration of equations (1)-(6) as a function of $M_{0}$ and $\beta_{1}$. Values of the parameters are as in Table 1. Panels B, E and F: corresponding stationary values obtained from the linear stability analysis of equations (18)-(22). Units: $M_{0}$ cells $/ \mathrm{mm}^{-3}$, $D$ percent of muscle cells, $\beta_{1}=\frac{10^{2} b_{1}}{d_{1}} \sim 104.56$ non-dimensional. 